\title{
Heterologous overexpression of Lithospermum erythrorhizon LeERF-1 gene increases drought and pathogen resistance in Arabidopsis
}

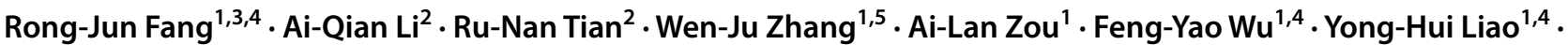 \\ Xiao-Ming Wang ${ }^{1,4} \cdot$ Yan-Jun Pang ${ }^{1} \cdot$ Rong-Wu Yang ${ }^{1} \cdot$ Gui-Hua Lu ${ }^{1,4} \cdot$ Jin-Liang $\mathrm{Qi}^{1,4} \cdot$ Yong-Hua Yang ${ }^{1,4}$
}

Received: 30 October 2017 / Revised: 20 June 2018 / Accepted: 2 January 2019 / Published online: 25 January 2019

(c) Franciszek Górski Institute of Plant Physiology, Polish Academy of Sciences, Kraków 2019

\begin{abstract}
Ethylene-responsive transcription factors (ERFs) belonging to the AP2/ERF family have diverse functions in plants. However, the functions of LeERF-1, a member of ERF family from the medicinal plant Lithospermum erythrorhizon, remain unclear. In this study, by cloning the promoter of $L e E R F-1$, we found that the promoter region contained a number of potential regulatory motifs related to drought and pathogen resistances. Further transgenic studies showed that the heterologous overexpression of LeERF-1 in Arabidopsis displayed phenotypes of higher survival ratio, lower root inhibition rate, slow water loss in leaf discs, and smaller stomatal apertures under drought stress, compared with wild type (WT) of Arabidopsis. LeERF-1 transgenic Arabidopsis also displayed fewer chlorotic symptoms, lower incidence rates, and lower levels of bacterial proliferation on leaves after the inoculation of bacterial pathogen compared with WT. These results suggested that $L e E R F-1$ can also confer drought and pathogen resistances. Our work provided a candidate gene with remarkable potential use in genetic engineering for stress resistance improvement in plants.
\end{abstract}

Keywords LeERF-1 $\cdot$ Heterologous overexpression $\cdot$ Drought $\cdot$ Pathogen $\cdot$ Arabidopsis $\cdot$ L. erythrorhizon

\section{Introduction}

During the courses of growth and development, plants are exposed to various biotic and abiotic stresses, such as pathogen infection and drought stress. Plants have evolved through

Communicated by Y. Wang.

Rong-Jun Fang, Ai-Qian Li and Ru-Nan Tian contributed equally to this work.

Electronic supplementary material The online version of this article (https://doi.org/10.1007/s11738-019-2807-z) contains supplementary material, which is available to authorized users.

Gui-Hua Lu

guihua.lu@nju.edu.cn

$\triangle$ Jin-Liang Qi

qijl@nju.edu.cn

Yong-Hua Yang

yangyh@nju.edu.cn

1 State Key Laboratory of Pharmaceutical Biotechnology, NJU-NJFU Joint Institute of Plant Molecular Biology, School of Life Sciences, Nanjing University, No. 163 Xianlin Avenue, Nanjing 210023, People's Republic of China a series of mechanisms to adapt to these environmental challenges at physiological and molecular levels (Duque et al. 2013; Gupta and Huang 2014; AbuQamar et al. 2017).

Under the drought stress condition, the plant adaptive mechanisms include diverse physiological alterations such as the retention of water, root modification, and morphological changes in stomatal behavior and leaves (Shulaev et al. 2008; Cao and Li 2010; Gechev and Hille 2012). The physiological changes are determined by molecular responses, eventually resulting in the adaptation to diverse stress challenges (Rejeb et al. 2014; Ramegowda and Senthilkumar 2015; Sham et al. 2015). One of the

2 College of Landscape Architecture, Nanjing Forestry University, Nanjing 210037, People's Republic of China

3 Jiangsu University of Science and Technology, Zhenjiang 212003, People's Republic of China

4 Co-Innovation Center for Sustainable Forestry in Southern China, Nanjing Forestry University, Nanjing 210037, People's Republic of China

5 School of Life Sciences, Shanghai University, Shanghai 200444, People's Republic of China 
most important mechanisms in keeping the environmental acclimatization is the activation of numerous stress-related genes, such as genes belonging to the transcription factor families of WRKY, myeloblastosis (MYB), and apetala2/ ethylene response factor (AP2/ERF), which confer to the metabolic adjustments of plants under both biotic and abiotic stresses ultimately (Pandey et al. 2015; Sham et al. 2014, 2017). The identification of stress-related genes is one of the most important strategies for understanding the complex molecular adaptation mechanisms of plants under stress conditions. Transcription factors can dramatically influence the stress resistance of plants by regulating the expression of a series of downstream genes involved in stress responses (Singh et al. 2002; Sudha and Ravishankar 2002; Harb et al. 2010).

Ethylene-responsive transcription factors (ERFs) are DNA-binding proteins belonging to the AP2/ERF family. These plant-specific transcription factors have been proven to be involved in plant growth and development, environmental adaptation, and stress resistance (Dietz et al. 2010). The subsets of ethylene responses are modulated by different ERFs (Fujimoto et al. 2000). To date, ERFs are involved in abiotic stress-induced responses in many plants, such as rice (Pegoraro et al. 2013; Santos et al. 2013), maize (Nguyen et al. 2009), tobacco (Zhang et al. 2009, 2016), and tomato (Pan et al. 2012). ERF proteins are also involved in defense responses to pathogen attacks. (Oñate-sánchez and Singh 2002; Zhang et al. 2004; Zuo et al. 2010).

We previously cloned a full-length cDNA of LeERF-1, a B3 subfamily member of AP2/ERF family, from the medicinal plant L. erythrorhizon, and reported that LeERF- 1 might be involved in light- and ethylene-regulated biosynthesis of secondary metabolites, shikonin and its derivatives, in $L$. erythrorhizon (Zhang et al. 2011).

Stress factors, such as low temperature, drought stress, and salt stress can alter the gene expression profile and influence the production of secondary metabolites (Rao and Ravishankar 2002; Ishita et al. 2010). Plants synthesize a diverse range of active secondary metabolites to protect themselves against a wide variety stresses (Dixon 2001; Iriti and Faoro 2009; Murcia et al. 2016). Therefore, efforts investigating the role of LeERF-1 on the molecular adaptation mechanisms of stresses are of fundamental importance to bridge the gap between stress response and secondary metabolism. However, the main function of LeERF-1 in stress response remains unclear.

In the current study, we cloned and characterized the promoter sequence of LeERF-1, and further clarified the role of $L e E R F-1$ in response to drought and pathogen stresses in transgenic Arabidopsis. This new understanding of the regulatory role of $L e E R F-1$ on stress resistance would allow a better manipulation and engineering of LeERF- 1 to enhance plant adaption to abiotic and biotic stresses.

\section{Materials and methods}

\section{Cloning and sequence analysis of the LeERF-1 promoter}

The promoter of $L e E R F-1$ was isolated from the genomic DNA of L. erythrorhizon using a thermal asymmetric interlaced (TAIL)-PCR (Liu et al. 1995; Liu and Whittier 1995; Siebert et al. 1995). PCR was performed using three $L e E R F$ 1 gene-specific primers ERF-GSP1, ERF-GSP2, and ERFGSP3 (Suppl. Table S1) with the random primer AP1 in the TaKaRa Genome Walking kit [TaKaRa Biotechnology (Dalian) Co., Ltd.]. The plant cis-acting regulatory DNA elements (PLACE) database (http://www.dna.affrc.go.jp/ $\mathrm{PLACE} /$ ) were used to identify the putative functional cisacting elements of the LeERF-1 promoter (Higo et al. 1999).

\section{Plant materials and growth conditions}

The seeds of Arabidopsis thaliana (Col-0 ecotype) transformed with the expression vector pBI121-LeERF-1-eGFP (Zhang et al. 2011) were surface-sterilized with $70 \%$ ethanol, washed five times with sterile water, and placed on $1 / 2$ MS medium. The overexpression of the LeERF-1 transgenic plants (35S:LeERF-1) was confirmed by both PCR analysis with the gene-specific primers (Suppl. Table S1) and subcellular localization of LeERF-1 protein as we previously reported (Zhang et al. 2011). The wild-type (WT) and 35S:LeERF-1 plants were grown at $23{ }^{\circ} \mathrm{C}$ with 16 -h-light/8h-dark cycle with $80 \%$ relative air humidity. Plants producing $100 \%$ kanamycin-resistant progenies in the T3 or T4 generation were considered homozygotes and were selected for transgenic analysis. The DNA of the transgenic plants above were used as template for PCR amplification of the inserted target sequence in the $\mathrm{pBI} 121-L e E R F-1$ vector using the primer pair 35S-F/GFP-R (Suppl. Table S1). Transgenic Arabidopsis lines conformed by RT-PCR were randomly selected and used for further studies (Suppl. Fig. S1).

\section{Drought stress treatments}

Three randomly selected transgenic Arabidopsis lines (OE9, OE-29, and OE-57) were stratified under $4{ }^{\circ} \mathrm{C}$ for 2 days on $1 / 2$ MS medium supplemented with or without $5 \%$ PEG and were germinated under normal growth condition $\left(23^{\circ} \mathrm{C}\right.$ with 16-h-light/8-h-dark cycle and relative air humidity was about $80 \%$ ). After 3 weeks, these were used for phenotypic observation and drought-resistant selection.

Seeds were germinated on a $1 / 2 \mathrm{MS}$ containing $5 \%$ PEG or without PEG for 2 weeks to measure the root lengths 
of the seedlings. Four-week-old leaves were punched into small discs and incubated in serial concentrations of PEG solution $(5 \%, 10 \%$, and $15 \%$, respectively) with the aqueous solution treatment as control. Phenotypic changes were observed after $72 \mathrm{~h}$.

Leaves of OE-9, OE-29, OE-57, and WT grown in soil pots were detached and placed on filter papers at the ambient environment for $0,10,30,60$, and $120 \mathrm{~min}$, respectively. The stomatal opening of guard cells in isolated epidermal tissues was captured using a confocal laser-scanning fluorescence microscope (U-RFL-T, Olympus, Japan).

The values are represented by means $\pm \operatorname{SD}(n=3)$, and the bars with different letters are significantly different at $P<0.05$ (lower letters) or $P<0.01$ (capital letters), respectively.

\section{Pathogen infection}

Four-week-old plants grown on soil under normal growth condition were used for pathogen infection. Pseudomonas syringae pv. tomato DC3000 (Pst. DC3000) was selected as the infection strain (Buell et al. 2003; Xin and He 2013; Bao et al. 2014; Chae Woo et al. 2014). This strain was cultured in liquid NYGB medium containing $50 \mu \mathrm{g} / \mathrm{mL}$ rifampicin and placed in a rotary shaker at $200 \mathrm{rpm}$ for $8-9 \mathrm{~h}$ at $28^{\circ} \mathrm{C}$. The sample was collected by centrifugation, and re-suspended in $10 \mathrm{mM} \mathrm{MgCl}_{2}$ containing $0.02 \%$ Silwet L-77 to a concentration of $\mathrm{OD}_{600}$ of about 0.1 . The inoculation of the bacteria-containing Arabidopsis leaf tissues was performed similar to the method described by Cao et al. (2005). After the inoculation, the plants were kept at $100 \%$ humidity for $24 \mathrm{~h}$ and then raised in a growth room at $25^{\circ} \mathrm{C}$ under the 16-h-light/8-h-dark condition.

The phenotypic observation was performed after 3 days of inoculation. The disease was evaluated based on the size of lesion and the bacterial population in leaf tissues (Cao et al. 2005).

To determine the bacterial growth, leaves for each inoculated plant were collected and placed in a $1.5-\mathrm{mL}$ centrifuge tube after 6 days of inoculation. Samples were vigorously shaken in the test tube with $1 \mathrm{~mL}$ of $10 \mathrm{mM} \mathrm{MgCl}$. Moreover, to count the number of spores, the leaves were removed, and the spore-containing suspension was centrifuged at $5000 \mathrm{~g}$ for $5 \mathrm{~min}$. The spores were re-suspended and counted with a blood cell counter (Bertoni and Mills 1987; Oh et al. 2005).

\section{Statistical analysis}

Statistical analyses were performed using the SPSS 17.0 software (IBM, IL, USA). One-way ANOVA and significant difference method (LSD) were used for the comparison between WT and LeERF-1 transgenic lines. The values are represented by means $\pm S D$, and the bars with different letters are significantly different at $P<0.05$ (lower letters) or $P<0.01$ (capital letters), respectively.

\section{Results}

\section{Cloning and sequence analysis of the LeERF-1 promoter region}

To understand the expression regulation of $L e E R F-1$, the promoter fragment of $L e E R F-1$ was isolated from the genomic DNA of L. erythrorhizon via genome-walking method (Suppl. Fig. S2), and 2615 bp of the PCR product (about 5000 bp) was obtained by walking sequencing from one end (GenBank Accession Number KX768421) after excluding the overlap with the cDNA sequence of LeERF-1. The putative cis-acting elements of the obtained promoter sequence were then analyzed. Results showed that the promoter sequence contains multiple potential regulatory motifs corresponding to several known cis-acting elements which are related to tissue-specific expression, phytohormones (abscisic acid, jasmonate, ethylene, salicylate, and gibberellic acid) regulation, secondary metabolism, and biotic (disease resistance) and abiotic stress (drought, cold, and salt) responses. In addition, seven light regulation elements, CIACADIANLELHC, DRECRTCOREAT, EBOXBNNAPA, IBOXCORE, INRNTPSADB, SORLIP2AT, and TBOXATGAPB, were also found in the promoter region (Suppl. Table S2).

\section{Overexpression of LeERF-1 improves drought resistance}

Based on the above bioinformatics analysis of the promoter sequence, we further tested whether the heterologous expression of LeERF-1 can actually affect the capacity of the transgenic Arabidopsis to tolerate drought stress.

We first checked the growth performance of germinated seedlings on a 1/2 MS medium with 5\% PEG. On 1/2 MS medium without PEG, no difference was observed on the seed germination (Suppl. Fig. S3) or seedling phenotypes (Suppl. Fig. S4) between WT and three transgenic Arabidopsis lines. However, all germinated seedlings on 1/2 MS medium with 5\% PEG showed visual drought-associated phenotype symptoms, such as leaf rolling and wilting, after 3 weeks. The seedlings of WT showed no greening and failed to survive after 3 weeks, whereas transgenic lines remained healthy and displayed higher survival ratio than WT, indicating that LeERF-1 transgenic Arabidopsis exhibited higher resistance to drought stress than WT (Fig. 1a).

Root elongation assays indicated that the seedlings of WT exhibited an apparently suppressed phenotype in terms 


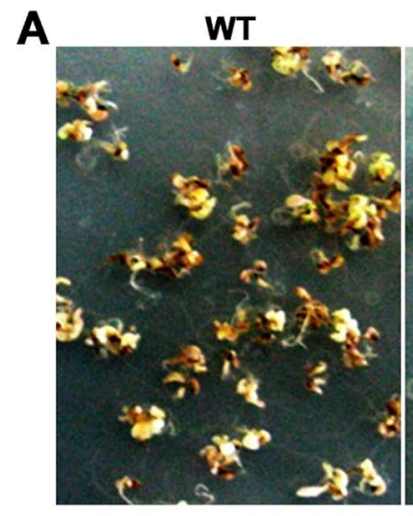

B

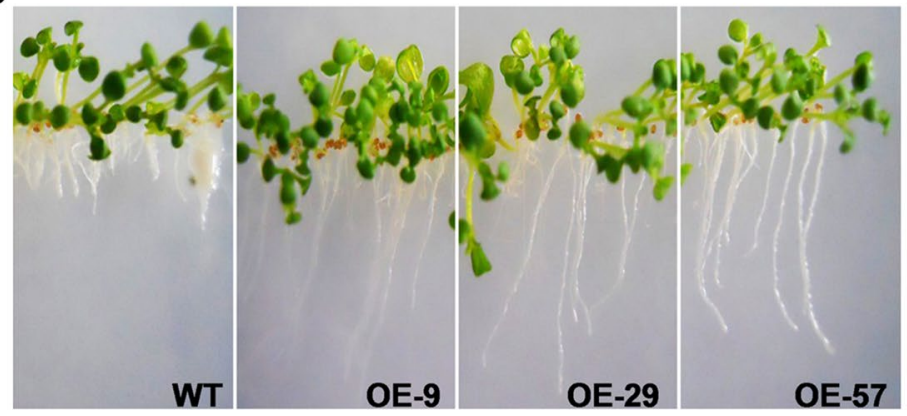

OE-9

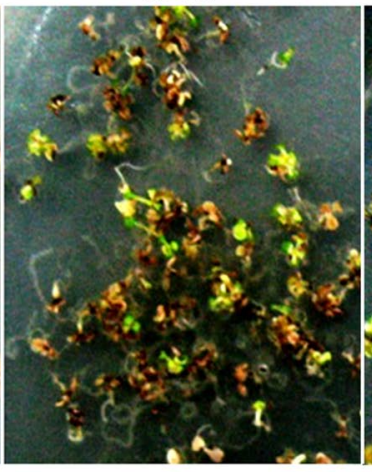

OE-57
OE-29

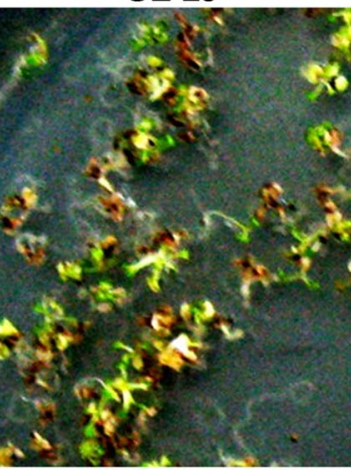

C

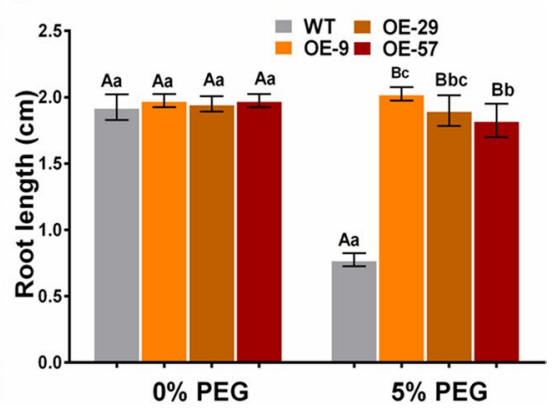

Fig. 1 The phenotype comparison between WT and three LeERF-1 transgenic Arabidopsis lines under simulated drought stress. a The phenotype of germinated seedlings of WT and three transgenic Arabidopsis lines on 1/2 MS medium with 5\% PEG for 3 weeks. b The comparison of root length between WT and transgenic Arabidopsis lines on 1/2 MS medium with 5\% PEG for 2 weeks. c The statistical comparison of root lengths between WT and LeERF-1 transgenic lines under simulated drought stress. The values are means $\pm \mathrm{SD}$, and the bars with different letters are significantly different at $P<0.05$ (lower letters) or $P<0.01$ (capital letters), respectively of root length when germinated on 1/2 MS medium with 5\% PEG (Fig. 1b). The root length of WT was significantly lower than that of the overexpressed transgenic seedlings $(P<0.01)$ (Fig. 1c). The longer root length of LeERF-1 transgenic plants was consistent with drought resistance phenotype as compared with WT.

We then checked the drought resistance by immersing the leaf discs prepared from 4-week-old plants for $72 \mathrm{~h}$ in water or in $5 \%, 10 \%$, and $15 \%$ PEG solution. With the different concentration of PEG, the leaf discs from WT exhibited more serious bleaching and necrosis when compared with those of the transgenic lines which appeared green and healthy (Fig. 2). These results suggest that the constitutive overexpression of LeERF-1 leads to the accelerated leaf drought resistance.

Considering the closure of stomata was correlated with the useful strategy for improving the efficient water use under water-limiting conditions (Tezara et al. 1999; Merlot et al. 2002), we conducted the examination of stomatal apertures under drought stress condition. The results showed no difference in stomatal pore size of plants before drought stress treatment. Drought treatment of guard cells of the isolated epidermal tissues induced the alterations of stomatal closure in WT and in all lines of LeERF-1 transgenic
Arabidopsis (Fig. 3a). Less stomatal opening of the guard cells was observed with the extension of drought stress time in each detected line. At each stress time points of 30,60, and 120 min, LeERF-1 transgenic Arabidopsis had significantly lower stomatal apertures compared to that of WT $(P<0.01)$ (Fig. 3b). The percentage of the stomatal aperture stomata in LeERF-1 transgenic Arabidopsis leaves was from 68.18 to $76.61 \%$ at 120 min stress point, compared with WT.

\section{Transgenic Arabidopsis of LeERF-1 confers improved resistance to pathogens}

The inoculation of the Arabidopsis leaf tissues with Pst. DC3000 was performed to determine whether the overexpression of LeERF-1 affects disease responses to bacterial pathogens. The leaves from WT exhibited more serious chlorotic symptoms of wilting and yellow spots after Pst. DC3000 inoculation for 3 days compared to the LeERF-1 transgenic Arabidopsis which did not exhibit visible macroscopic signs of infection after 3 days. After 6 days of bacterial inoculation, the leaves of WT appeared completely wilted; in contrast, LeERF-1 transgenic Arabidopsis lines exhibited fewer chlorotic symptoms compared with WT at 6 days after inoculation (Fig. 4a). The 
Fig. 2 The phenotype comparison of leaf discs between WT and transgenic lines immersed into aqueous solution and 5\%, $10 \%$, and $15 \%$ PEG stress treatments for $72 \mathrm{~h}$

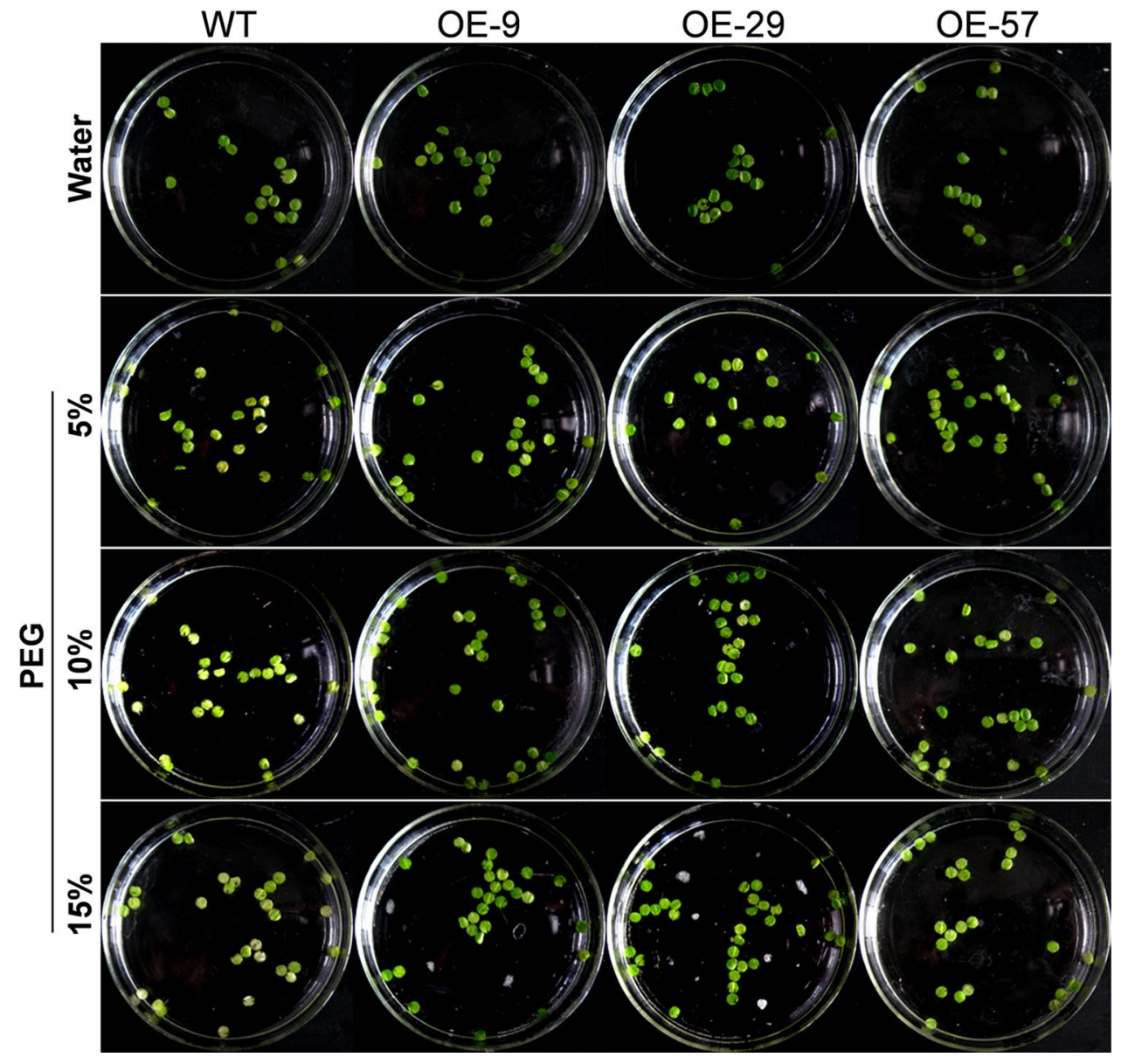

incidence rates of leaves from LeERF-1 transgenic Arabidopsis were significantly lower than that of WT infected with Pst. DC3000 strains after 3 and 6 days of inoculation $(P<0.01)$ (Fig. 4b). This result indicates a heterologous overexpression of $L e E R F-1$ enhanced resistance to bacterial pathogen Pst. DC3000.

Furthermore, we speculated that these chlorotic symptoms might reflect bacterial multiplication inside the leaf tissues. To confirm this speculation, the bacterial population on the leaves of the WT and LeERF-1 transgenic Arabidopsis lines was measured. After treatment with Pst. DC3000 for 6 days, the bacterial growth in both the WT and LeERF-1 transgenic Arabidopsis lines increased significantly. Consistent with the visible symptoms, LeERF-1 transgenic Arabidopsis lines exhibited significantly lower levels of bacterial proliferation than that of WT plants after 6 days of inoculation $(P<0.01)$ (Fig. 4c).

Therefore, these results indicated that the heterologous overexpression of LeERF-1 may synergistically contribute to the plant immune system for resisting the attack of bacterial pathogen Pst. DC3000.

\section{Discussion}

AP2/ERF is a large family of transcription factors in the ethylene signaling transduction pathway in plants. Based on the amino acid sequence similarity of the AP2/ERF DNAbinding domain, these AP2/ERF transcription factors in Arabidopsis are classified into five groups: AP2 subfamily, DREB subfamily, ERF subfamily, RAV subfamily and one very specific gene, At4g13040. The ERF subfamily and DREB subfamily can be further divided into several subgroups (Gutterson and Reuber 2004; Thamilarasan et al. 2014; Dossa et al. 2016). Accumulating evidence have suggested that a number of ERF members participate in the regulation of biotic and abiotic stress responses (Oñate-Sánchez et al. 2007; Pan et al. 2012; Zhang et al. 2012, 2016).

Although the AP2/ERF family has been widely studied in various plants, the current study is the first report on the role of LeERF-1, a B3 subfamily member of AP2/ERF from the medicinal plant L. erythrorhizon, based on its pathogen and drought stress responses in transgenic Arabidopsis. 
Fig. 3 The stomatal opening assay of LeERF-1-overexpressing transgenic plants in soil pots. Leaves were detached and placed on filter papers at ambient environment for 0,30 , 60 , and $120 \mathrm{~min}$, respectively. The stomatal opening of guard cells in isolated epidermal tissues was imaged using a confocal laser-scanning fluorescence microscope (a). The data were statistically analyzed (b), in which the values are means $\pm \mathrm{SD}(n=3)$ and the bars with capital letters indicate significant differences at $P<0.01$ (least significant difference)

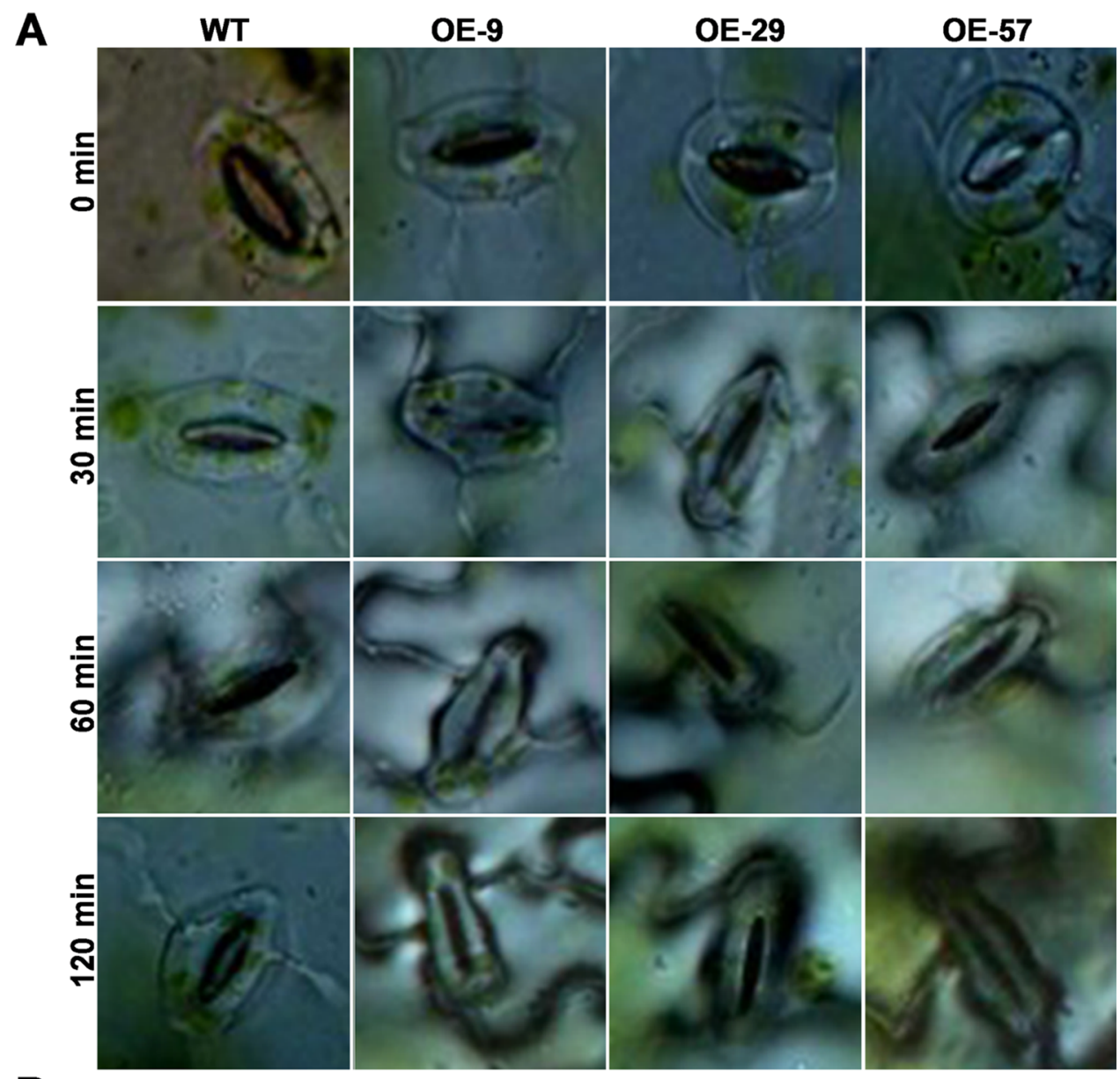

B

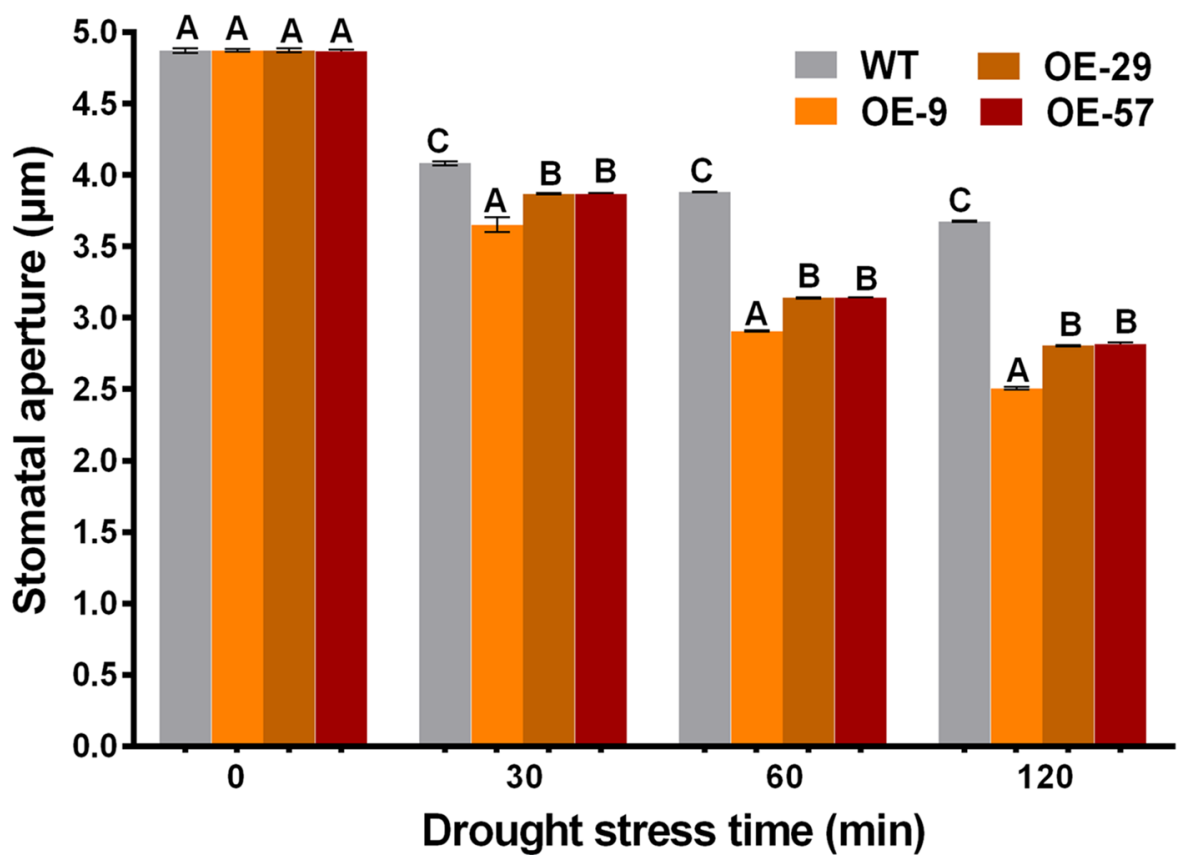

Our previous study reported that the light-regulated LeERF-1 was possibly involved in the biosynthesis of shikonin and its derivatives, the secondary metabolites of $L$. erythrorhizon. To test whether LeERF-1 can also confer stress responses and to verify the presence of stress response cis-elements in this region, we first cloned and characterized 
Fig. 4 The pathogen infection assay of LeERF-1-overexpressing transgenic plants. a The chlorotic symptoms of WT and LeERF-1 transgenic Arabidopsis plants infected with $P$. syringae DC3000 (Pst.DC3000) strains after 6 days of inoculation. $\mathbf{b}$ The incidence rates of leaves from WT and LeERF-1 transgenic Arabidopsis plants infected with Pst DC3000 strains at 3 and 6 days after inoculation. $\mathbf{c}$ The bacterial population from the leaves of WT and transgenic Arabidopsis lines infected with Pst. DC3000 strains at 6 days after inoculation. The values are means $\pm S D$ $(n=3)$, and the bars with different letters are significantly different at $P<0.05$ (lower letters) or $P<0.01$ (capital letters), respectively
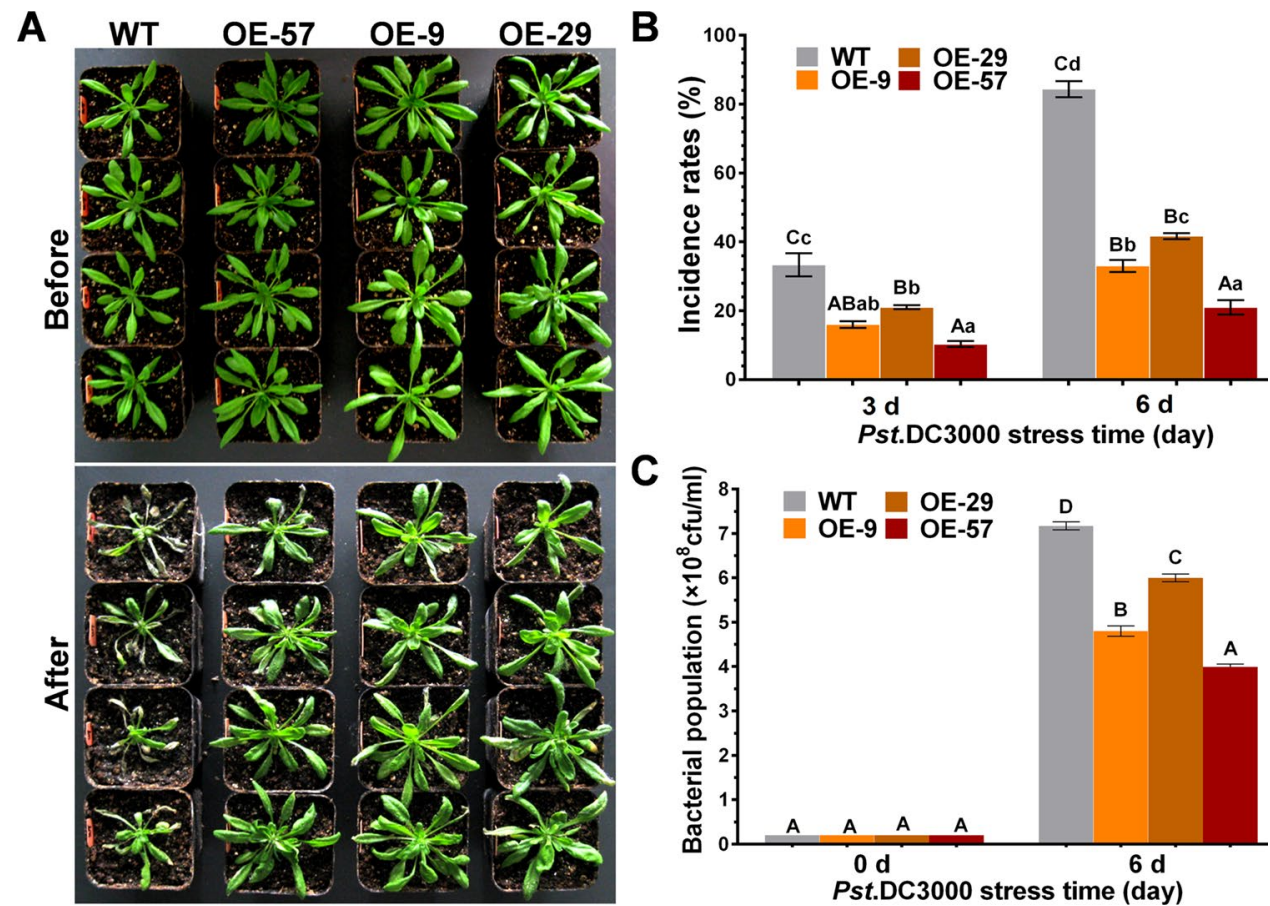

the promoter sequence of $L e E R F-1$. The PLACE analysis showed that the promoter of LeERF-1 contains different potential regulatory motifs which are corresponding to the diverse stress responses. We presumed that the expression of LeERF-1 may be driven by multiple stress-related regulators.

With the heterologous overexpression in A. thaliana, we investigated the role of $L e E R F-1$ on the molecular adaptation mechanisms to drought stress. Results showed that the LeERF-1 transgenic Arabidopsis seedlings displayed healthy phenotype, higher survival ratio, lower root inhibition rate, slower water loss, and smaller stomatal apertures under the drought stresses, compared with WT. The drought resistance phenotype of LeERF-1 transgenic plants was consistent with slower water loss in leaf discs and stomatal opening of the guard cells as compared with the WT.

Given the growth and development dependence of plants on the tight regulation of water uptake by root growth and stomata closure under drought stress condition, we hypothesized that the proper regulation of LeERF-1 might be necessary for proper root elongation to absorb water. In addition, the overexpression of LeERF-1 might alter the proper stomatal behavior to conserve water by reducing water loss. However, this hypothesis needs to be further identified.

In summary, these results indicated that the heterologous expression of LeERF-1 enables the Arabidopsis to have more adaptive abilities for growth under drought stress condition, i.e., the LeERF-1 confers enhanced drought stress resistance in plant.

The regulation of $\mathrm{AP} 2 / \mathrm{ERF}$ transcription factors in plant physiological and developmental processes have been extensively documented (Dietz et al. 2010; Zhang et al. 2012; Cheng et al. 2013). The ERF subfamily factors are mainly involved in response to biotic stresses such as pathogenesis (Oñatesánchez and Singh 2002; Zhang et al. 2004, 2009; Dossa et al. 2016).

Until recently, systematic profiling of genomics, transcriptomics, proteomics, and metabolomics can be a potential solution to the pathogenesis of human pandemic influenza viruses and plant diseases (Abuqamar et al. 2016; Tisoncikgo et al. 2016). Since the pathogen Pst. DC3000 has been used as a model for plant-pathogen interactions (Buell et al. 2003; Xin and He 2013; Bao et al. 2014; Chae Woo et al. 2014), we also analyzed the response of transgenic Arabidopsis seedlings overexpressing LeERF-1 under Pst. DC3000 infection.

In our current study, the seedlings of LeERF- 1 transgenic Arabidopsis showed fewer chlorotic symptoms, lower incidence rates, and lower levels of bacterial proliferation on leaves after inoculation of bacterial pathogen, compared with that of WT. Results suggested that LeERF-1 also plays various important roles in regulating plant responses to pathogen attacks. Our studies of LeERF- 1 function on the plant resistance to bacterial pathogen will also provide a foundation for genetic manipulation and breeding programs in the L. erythrorhizon and in other plants.

The regulation of ERFs in plant growth, development, and response to different environmental stress factors have been extensively documented (Dietz et al. 2010; Zhang et al. 2012; Cheng et al. 2013; Dossa et al. 2016). On the other hand, the diverse stress factors can alter the expression 
profile of stress-related genes and influence the production of secondary metabolites to protect themselves against a wide variety stresses (Dixon 2001; Rao and Ravishankar 2002; Iriti and Faoro 2009). As an ERF subfamily member, $L e E R F-1$ has been involved in the ethylene-regulated biosynthesis of shikonin and its derivatives in L. erythrorhizon (Zhang et al. 2011).

Therefore, our study on the role of $L e E R F-1$ under diverse stress conditions will help us further understand the relationship between the molecular adaptation mechanisms of stresses and secondary metabolism in the medicinal plant $L$. erythrorhizon in the future. We speculated that the accumulation of LeERF-1 transcripts enhances disease and stress resistance, which in turn correlated with the induction of shikonin production for more adaptive abilities in the growth of $L$. erythrorhizon. Further research on the exact function of LeERF-1 in L. erythrorhizon experiencing stresses will provide direct evidence for the induction of stress responses such as the specialized metabolite production of shikonin.

In conclusion, the heterologous overexpression of LeERF$l$ gene reveals its regulating role in response of pathogen attack and drought stress. Our results showed that LeERF$l$ is an attractive engineering target gene conferring stress resistance. This work might help to provide a useful tool to understand the complicated relationship between stressrelated genes and the biosynthesis of secondary metabolites in L. erythrorhizon in the future.

\section{Author contribution statement RJF, GHL, JLQ and YHY} designed the research and wrote the paper; RJF, AQL, RNT, WJZ, ALZ, FYW and YHL performed the experiments and analyzed the data; XMW, YJP and RWY discussed the results.

Acknowledgements This work was supported by the National Natural Science Foundation of China (NSFC) (31470384, 31670298, 31171161), the Natural Science Foundation of the Jiangsu Bureau of Science and Technology (BK2008265) and the Program for Changjiang Scholars and Innovative Research Team in University (IRT_14R27).

\section{Compliance with ethical standards}

Conflict of interest The authors declare that they have no conflict of interest.

\section{References}

Abuqamar SF, Moustafa K, Tran LS (2016) 'Omics' and plant responses to Botrytis cinerea. Front Plant Sci 7:1-8

AbuQamar S, Moustafa K, Tran LS (2017) Mechanisms and strategies of plant defense against Botrytis cinerea. Crit Rev Biotechnol $37: 262-274$
Bao Z, Stodghill PV, Myers CR, Lam H, Wei HL, Chakravarthy S, Kvitko BH, Collmer A, Cartinhour SW, Schweitzer P (2014) Genomic plasticity enables phenotypic variation of Pseudomonas syringae pv. tomato DC3000. PLoS One 9:e86628

Bertoni G, Mills D (1987) A simple method to monitor growth of bacterial populations in leaf tissue. Phytopathology 77:832-835

Buell CR, Joardar V, Lindeberg M, Selengut J, Paulsen IT, Gwinn ML, Dodson RJ, Deboy RT, Durkin AS, Kolonay JF (2003) The complete sequence of the Arabidopsis and tomato pathogen Pseudomonas syringae pv. tomato DC3000. Proc Natl Acad Sci USA 100:10181-10186

Cao M, Li X (2010) Die for living better: plants modify root system architecture through inducing PCD in root meristem under severe water stress. Plant Signal Behav 5:1645-1646

Cao Y, Wu Y, Zheng Z, Song F (2005) Overexpression of the rice EREBP-like gene OsBIERF3 enhances disease resistance and salt tolerance in transgenic tobacco. Physiol Mol Plant Pathol 67:202-211

Chae Woo L, Sheng L, Sung Chul L (2014) A prominent role for RCAR3-mediated ABA signaling in response to Pseudomonas syringae pv. tomato DC3000 infection in Arabidopsis. Plant Cell Physiol 55:1691-1703

Cheng MC, Liao PM, Kuo WW, Lin TP (2013) The Arabidopsis ETHYLENE RESPONSE FACTOR1 regulates abiotic stress-responsive gene expression by binding to different $c i s$-acting elements in response to different stress signals. Plant Physiol 162:1566-1582

Dietz KJ, Vogel MO, Viehhauser A (2010) AP2/EREBP transcription factors are part of gene regulatory networks and integrate metabolic, hormonal and environmental signals in stress acclimation and retrograde signalling. Protoplasma 245:3-14

Dixon RA (2001) Natural products and plant disease resistance. Nature 411:843-847

Dossa K, Xin W, Li D, Fonceka D, Zhang Y, Wang L, Yu J, Liao B, Diouf D, Cissé N (2016) Insight into the AP2/ERF transcription factor superfamily in sesame and expression profiling of DREB subfamily under drought stress. BMC Plant Biol 16:171

Duque AS, Almeida AMD, Silva ABD, Silva JMD, Farinha AP, Santos D, Fevereiro P, Araújo SDS (2013) Abiotic stress responses in plants: unraveling the complexity of genes and networks to survive. Intech 105:1115-1126

Fujimoto SY, Ohta M, Usui A, Shinshi H, Ohme-Takagi M (2000) Arabidopsis ethylene-responsive element binding factors act as transcriptional activators or repressors of GCC box-mediated gene expression. Plant Cell 12:393-404

Gechev TS, Hille J (2012) Molecular basis of plant stress. Cell Mol Life Sci 69:3161-3163

Gupta B, Huang B (2014) Mechanism of salinity tolerance in plants: physiological, biochemical, and molecular characterization. Intl J Genom 2014:1-18

Gutterson N, Reuber TL (2004) Regulation of disease resistance pathways by AP2/ERF transcription factors. Curr Opin Plant Biol $7: 465-471$

Harb A, Krishnan A, Ambavaram MMR, Pereira A (2010) Molecular and physiological analysis of drought stress in Arabidopsis reveals early responses leading to acclimation in plant growth. Plant Physiol 154:1254-1271

Higo K, Ugawa Y, Iwamoto M, Korenaga T (1999) Plant cis-acting regulatory DNA elements (PLACE) database: 1999. Nucleic Acids Res 27:297-300

Iriti M, Faoro F (2009) Chemical diversity and defence metabolism: how plants cope with pathogens and ozone pollution. Int J Mol Sci 10:3371-3399

Ishita A, De Vos RCH, Bones AM, Hall RD (2010) Plant molecular stress responses face climate change. Trends Plant Sci 15:664-674

Liu YG, Whittier RF (1995) Thermal asymmetric interlaced PCR: automatable amplification and sequencing of insert end fragments 
from P1 and YAC clones for chromosome walking. Genomics 25:674-681

Liu YG, Mitsukawa N, Oosumi T, Whittier RF (1995) Efficient isolation and mapping of Arabidopsis thaliana T-DNA insert junctions by thermal asymmetric interlaced PCR. Plant J 8:457-463

Merlot S, Mustilli AC, Genty B, North H, Lefebvre V, Sotta B, Vavasseur A, Giraudat J (2002) Use of infrared thermal imaging to isolate Arabidopsis mutants defective in stomatal regulation. Plant J 30:601-609

Murcia G, Fontana A, Pontin M, Baraldi R, Bertazza G, Piccoli PN (2016) ABA and GA3 regulate the synthesis of primary and secondary metabolites related to alleviation from biotic and abiotic stresses in grapevine. Phytochemistry 135:34-52

Nguyen HT, Leipner J, Stamp P, Guerra-Peraza O (2009) Low temperature stress in maize (Zea mays L.) induces genes involved in photosynthesis and signal transduction as studied by suppression subtractive hybridization. Plant Physiol Biochem 47:116-122

Oh IS, Park AR, Bae MS, Kwon SJ, Kim YS, Lee JE, Kang NY, Lee S, Cheong H, Park OK (2005) Secretome analysis reveals an Arabidopsis lipase involved in defense against Alternaria brassicicola. Plant Cell 17:2832-2847

Oñatesánchez L, Singh KB (2002) Identification of Arabidopsis ethylene-responsive element binding factors with distinct induction kinetics after pathogen infection. Plant Physiol 128:1313-1322

Oñate-Sánchez L, Anderson JP, Young J, Singh KB (2007) AtERF14, a member of the ERF family of transcription factors, plays a nonredundant role in plant defense. Plant Physiol 143:400-409

Pan Y, Seymour GB, Lu C, Hu Z, Chen X, Chen G (2012) An ethylene response factor (ERF5) promoting adaptation to drought and salt tolerance in tomato. Plant Cell Rep 31:349-360

Pandey P, Ramegowda V, Senthilkumar M (2015) Shared and unique responses of plants to multiple individual stresses and stress combinations: physiological and molecular mechanisms. Front Plant Sci 6:723

Pegoraro C, Farias DDR, Mertz LM, Santos RSD, Maia LCD, Rombaldi CV, Oliveira ACD (2013) Ethylene response factors gene regulation and expression profiles under different stresses in rice. Theor Exp Plant Physiol 25:261-274

Ramegowda V, Senthilkumar M (2015) The interactive effects of simultaneous biotic and abiotic stresses on plants: mechanistic understanding from drought and pathogen combination. J Plant Physiol 176:47-54

Rao SR, Ravishankar GA (2002) Plant cell cultures: chemical factories of secondary metabolites. Biotechnol Adv 20:101-153

Rejeb IB, Pastor V, Mauch-Mani B (2014) Plant responses to simultaneous biotic and abiotic stress: molecular mechanisms. Plants $3: 458$

Santos RSD, Krüger MM, Pegoraro C, Madabula FP, Maia LCD, Rombaldi CV, Oliveira ACD (2013) Transcriptional regulation of seven ERFs in rice under oxygen depletion and iron overload stress. Trop Plant Biol 6:16-25

Sham A, Alazzawi A, Alameri S, Almahmoud B, Awwad F, Alrawashdeh A, Iratni R, Abuqamar S (2014) Transcriptome analysis reveals genes commonly induced by Botrytis cinerea infection, cold, drought and oxidative stresses in Arabidopsis. PLoS One 9:e113718

Sham A, Moustafa K, Alameri S, Alazzawi A, Iratni R, Abuqamar S (2015) Identification of Arabidopsis candidate genes in response to biotic and abiotic stresses using comparative microarrays. PLoS One 10:e 0125666

Sham A, Moustafa K, Alshamisi S, Alyan S, Iratni R, Abuqamar S (2017) Microarray analysis of Arabidopsis WRKY33 mutants in response to the necrotrophic fungus Botrytis cinerea. PLoS One 12: 0172343

Shulaev V, Cortes D, Miller G, Mittler R (2008) Metabolomics for plant stress response. Physiol Plant 132:199-208

Siebert PD, Chenchik A, Kellogg DE, Lukyanov KA, Lukyanov SA (1995) An improved PCR method for walking in uncloned genomic DNA. Nucleic Acids Res 23:1087-1088

Singh KB, Foley RC, Oñate-Sánchez L (2002) Transcription factors in plant defence and stress responses. Curr Opin Plant Biol $5: 430-436$

Sudha G, Ravishankar GA (2002) Involvement and interaction of various signaling compounds on the plant metabolic events during defense response, resistance to stress factors, formation of secondary metabolites and their molecular aspects. Plant Cell Tiss Organ Cult 71:181-212

Tezara W, Mitchell VJ, Driscoll SD, Lawlor DW (1999) Water stress inhibits plant photosynthesis by decreasing coupling factor and ATP. Nature 401:914-917

Thamilarasan SK, Park JI, Jung HJ, Nou IS (2014) Genome-wide analysis of the distribution of AP2/ERF transcription factors reveals duplication and $\mathrm{CBF}$ genes elucidate their potential function in Brassica oleracea. BMC Genom 15:1-13

Tisoncikgo J, Gasper DJ, Kyle JE, Eisfeld AJ, Selinger C, Hatta M, Morrison J, Korth MJ, Zink EM, Kim YM (2016) Integrated omics analysis of pathogenic host responses during pandemic H1N1 influenza virus infection: the crucial role of lipid metabolism. Cell Host Microbe 19:254-266

Xin XF, He SY (2013) Pseudomonas syringae pv. tomato DC3000: a model pathogen for probing disease susceptibility and hormone signaling in plants. Annu Rev Phytopathol 51:473-498

Zhang H, Zhang D, Chen J, Yang Y, Huang Z, Huang D, Wang XC, Huang R (2004) Tomato stress-responsive factor TSRF1 interacts with ethylene responsive element GCC box and regulates pathogen resistance to Ralstonia solanacearum. Plant Mol Biol $55: 825-834$

Zhang G, Chen M, Li L, Xu Z, Chen X, Guo J, Ma Y (2009) Overexpression of the soybean GmERF3 gene, an AP2/ERF type transcription factor for increased tolerances to salt, drought, and diseases in transgenic tobacco. J Exp Bot 60:3781-3796

Zhang W, Zou A, Miao J, Yin Y, Tian R, Pang Y, Yang R, Qi J, Yang $\mathrm{Y}$ (2011) LeERF-1, a novel AP2/ERF family gene within the B3 subcluster, is down-regulated by light signals in Lithospermum erythrorhizon. Plant Biol 13:343-348

Zhang Z, Wang J, Zhang R, Huang R (2012) The ethylene response factor AtERF98 enhances tolerance to salt through the transcriptional activation of ascorbic acid synthesis in Arabidopsis. Plant J 71:273-287

Zhang H, Li A, Zhang Z, Huang Z, Lu P, Zhang D, Liu X, Zhang ZF, Huang R (2016) Ethylene response factor TERF1, regulated by ETHYLENE-INSENSITIVE3-like factors, functions in reactive oxygen species (ROS) scavenging in tobacco (Nicotiana tabacum L.). Sci Rep 6:29948

Zuo KJ, Qin J, Zhao JY, Ling H, Zhang LD, Cao YF, Tang KX (2010) Over-expression $G b E R F 2$ transcription factor in tobacco enhances brown spots disease resistance by activating expression of downstream genes. Ther Adv Respir Dis 4:271-278

Publisher's Note Springer Nature remains neutral with regard to jurisdictional claims in published maps and institutional affiliations. 